\title{
Experimental and simulation studies on compressive properties of brazed aluminum honeycomb plate and a strength prediction method
}

\author{
Lanxin Jiang ${ }^{1}$, Shoune Xiao², Jingke Zhang ${ }^{2}$, Ruijuan $\mathrm{Lv}^{2}$, Bing Yang${ }^{1}$, Dawei Dong ${ }^{2}$, \\ GUANGWU YANG ${ }^{1}$, and Tao Zhu ${ }^{1}$
}

${ }^{1}$ Affiliation not available

${ }^{2}$ Southwest Jiaotong University

July 14, 2020

\begin{abstract}
To study the compressive mechanical properties of a new type of brazed aluminum honeycomb plate (BAHP), tensile tests on single- and brazed-cell walls as well as compression tests in the out-of-plane, in-plane longitudinal, and transverse directions were conducted. Compared to the material properties of a traditional glued aluminum honeycomb plate (GAHP), those of the singleand brazed-cell walls of the BAHP are entirely different. Therefore, their characteristics should be considered separately when performing theoretical and simulation analysis. Under out-of-plane compression, the core of the BAHP did not debond, owing to its higher strength than that of the GAHP. In comparison, under in-plane compression in the longitudinal and transverse directions, the load-displacement characteristics, ultimate load, and failure modes also differed, and there was no large-scale cracking. Considering the characteristics of the BAHP, a strength prediction method was proposed. The simulation results demonstrated that the model built based on the new method was highly consistent with the experimental results.
\end{abstract}

\section{Hosted file}

honeycomb-ffems.docx available at https://authorea.com/users/342582/articles/469382experimental-and-simulation-studies-on-compressive-properties-of-brazed-aluminumhoneycomb-plate-and-a-strength-prediction-method 